\title{
Nursing care for patients with non-small cell lung cancer receiving adjuvant chemotherapy: Evidence-based implications for practice
}

\author{
by Lorraine Martelli-Reid, Sue Baker, Christopher A. Smith, \\ Christina Lacchetti, Yee C. Ung, William K. Evans, and \\ members of the Lung Cancer Disease Site Group of Cancer \\ Care Ontario's Program in Evidence-Based Care
}

\section{Abstract}

Oncology nurses provide care to patients and their families across the cancer care continuum including counselling patients on issues related to treatment completion, providing education directed towards the prevention of side effects, assessing and managing symptoms, and follow-up. Believing that a nursing-specific perspective related to these concerns was necessary to improve care for patients with resected, non-small cell lung cancer (NSCLC) receiving adjuvant chemotherapy, a nursing guidance report was initiated. This report was developed by utilizing evidence retrieved in a practice guideline report, general principles established by CANO/ACIO, Fitch's supportive care model, and the clinical experiences of Lung DSG members. Evidence on the toxicity and adverse events that are caused by adjuvant chemotherapy and side effects and symptoms that are amenable to nursing intervention are highlighted and discussed.

\section{Background}

The Lung Cancer Disease Site Group (Lung DSG) of the Cancer Care Ontario (CCO) Program in Evidence-based Care (PEBC) has developed a clinical practice guideline, based on a systematic review of the evidence, for the medical use of postoperative chemotherapy in completely resected NSCLC (Alam et al., 2006). That guideline

Lorraine Martelli-Reid, RN, MN, Juravinski Cancer Centre at Hamilton Health Sciences and McMaster University, Hamilton, ON.

Sue Baker, RN, MScN, London Health Sciences Centre, London Regional Cancer Program London, ON.

Christopher A. Smith, MSc, Cancer Care Ontario Program in Evidence-based Care, McMaster University, Hamilton, ON.

Christina Lacchetti, MHSc, Cancer Care Ontario Program in Evidence-based Care, McMaster University, Hamilton, ON.

Yee C. Ung, MD, FRCPC, Odette Cancer Centre and University of Toronto, Toronto, $\mathrm{ON}$.

William K. Evans, MD, FRCPC, Odette Cancer Centre and University of Toronto, Toronto, $O N$.

Please see the Program in Evidence-based Care section of Cancer Care Ontario's Web site for a list of current Disease Site Group members (http://www.cancercare.on.ca/).

Corresponding author: Ms. Lorraine Martelli-Reid clo Christina Lacchetti, Cancer Care Ontario Program in Evidence-Based Care, McMaster University Downtown Campus, 1280 Main St. West, Hamilton, ON L8S 4L8. E-mail: lacchet@mcmaster.ca recommended cisplatin-based chemotherapy as postoperative treatment for patients with completely resected stage II or IIIA disease who are considered fit enough for chemotherapy. Therapy was not recommended for patients with stage IB disease.

These treatment recommendations have broader implications for the management of patients, because chemotherapy-related toxicities need to be appropriately assessed and managed for patients to receive the optimal benefits of therapy. The practice guideline report emphasizes that the potential benefits, limitations, and toxicity of adjuvant treatment should be fully discussed with patients, and the importance of effective management of disease and treatment-related symptoms is increasingly recognized (Alam et al., 2006). Members of the Lung DSG noted that there is a widely recognized difficulty keeping patients on adjuvant therapy, because of side effects. Nurses fill a number of roles across the continuum of care, including counselling patients on issues related to treatment completion, providing education directed towards the prevention of side effects, assessing and managing symptoms of the disease or previous surgery, and follow-up. Believing that a nursingspecific perspective related to these concerns was necessary to improve care for NSCLC patients receiving adjuvant chemotherapy, the Lung DSG members initiated this nursing guidance report.

This report is intended to be a resource for nurses caring for patients with NSCLC who are receiving adjuvant chemotherapy. In this report, we review the evidence on toxicity and adverse events from adjuvant chemotherapy and highlight priority side effects that are amenable to nursing assessment and intervention. For each of the major side effects, assessment and management strategies are highlighted, as is advice for meeting patients' informational, physical, and emotional needs throughout the treatment trajectory. The Standards of Care developed by the Canadian Association of Nurses in Oncology/L'Association canadienne des infirmières en Oncologie (CANO/ACIO) detail key aspects of effective practice in this setting and form a basis for the advice provided in this report (Canadian Association of Nurses in Oncology, 2002).

\section{Methods}

A systematic review and clinical practice guideline on adjuvant chemotherapy in resected NSCLC was developed by the Lung DSG in 2006 (Alam et al., 2006). This nursing document was initiated as an adjunct to that report. A literature search strategy was designed to identify published nursing practice guidelines and evidence-based reports that addressed care for patients with NSCLC receiving chemotherapy. The search included the following databases and periods: AMED (Allied and Complementary Medicine) 1985 to January 2007, CINAHL (Cumulative Index to Nursing \& Allied Health Literature) 1982 to February Week 1 2007, EMBASE 1980 to 2007 Week 5, Health and Psychosocial Instruments 1985 to January 2007, Ovid MEDLINE(R) In-Process \& Other Non-Indexed Citations February 06, 2007, Ovid MEDLINE(R) 1950 to January Week 4 2007, PsycINFO 1806 to January Week 5 2007, the Canadian Medical Association Infobase (http://mdm.ca/cpgsnew/cpgs/index.asp), and the National Guidelines Clearinghouse (http://www.guideline.gov/browse/guideline_index.aspx). The search was structured using various key terms for "guideline," "lung cancer," 
and "nursing." Additional literature not published in academic journals was located through web searches of prominent professional websites or from authors' files, and also included. For additional data on chemotherapy side effects, the electronic version of the Compendium of Pharmaceuticals and Specialities of the Canadian Pharmacists Association (http://e-cps/pharmacists.ca/CPHA/) and the Cancer Care Ontario Formulary (http://www.cancercare.on.ca/ english/toolbox/drugs/drugformulary/) were searched.

While a structured literature search was conducted for published practice guidelines on topics in lung cancer nursing, the two guidelines found were not based on evidence or specific to the scope of this report (The London and South East Lung Cancer Forum for Nurses, 2004; Quinn, 1999). Instead, therefore, the Lung DSG developed nursing-specific guidance on this topic by utilizing evidence retrieved in the medical practice guideline report (Alam et al., 2006), general principles established by CANO/ACIO for nursing oncology practice (Canadian Association of Nurses in Oncology, 2002), the Fitch model identifying patient and family domains of need across the cancer care continuum (Fitch, 2003; Fitch, 1994), and the clinical experiences of Lung DSG members.

\section{Guidance}

Standards of care, nursing roles, and competencies

CANO/ACIO statements on nursing standards, roles, and competencies underpin quality nursing practice for patients with lung cancer. These statements are broad in their scope and are applicable to nurses working across all disease sites, including lung cancer. Although the CANO/ACIO statements are valuable as broad guiding principles for nursing practice, more specific guidance is needed on issues that arise in the care of patients receiving adjuvant chemotherapy for resected NSCLC. Lung DSG members reviewed and extended the CANO/ACIO standards of care in order to develop practice-specific guidance for nurses working in this setting. The CANO/ACIO standards reflect the belief that patients are entitled to the following care elements: individualized and holistic care; familycentred care; self-determination and access to information to enable decision-making; seamless, coordinated, and continuous care involving open lines of communication and access to the interdisciplinary team; supportive, knowledgeable, and professional therapeutic relationships; and evidence-based and ethical care in which meticulous symptom management and health promotion is the primary focus. The Lung DSG recommends that nurses caring for patients receiving adjuvant chemotherapy for resected NSCLC adhere to these statements in their practice.

In addition, the Fitch model (Fitch, 1994), which integrates six identified patient and family domains of need (physical, emotional, informational, psychosocial, spiritual, and practical) with nine points of care delivery across the continuum of the cancer journey (prediagnosis, diagnosis, dialogue/referral, treatment, rehabilitation, survivorship, recurrent disease, palliation, and bereavement) is a useful conceptual tool to guide nursing practice and underpins much of the following guidance (Fitch, 2003; Fitch, 1994). As the model indicates, individuals enter the cancer care delivery system at various points and experience the journey in different ways over time. As patients and their family members move along the cancer care trajectory, they bring their physical, emotional, psychological, social, informational, practical, and spiritual needs with them. These needs ebb and flow as a result of the disease itself, treatment effects and toxicities, and interactions with health care personnel. At each phase of the cancer journey, needs will emerge, change in intensity and resolve. If needs remain unmet, patients continue to experience physical and or emotional distress and upheaval. Emotional and physical distress can magnify and compromise compliance with cancer therapy (Carlson \& Bultz, 2004; Douillard et al., 2005; Shepherd et al., 2004) and increase patients' use of community health services and visits to emergency departments (Carlson \& Bultz, 2004; Kurtz, Kurtz, Given, \& Given, 2006).

\section{Beginning adjuvant treatment}

Application of Fitch's Supportive Care Model (Fitch, 2003; Fitch, 2004) and guidance through the CANO/ACIO documents help the oncology nurse to meet the following identified patient needs. The need for information is high as patients and their families enter the cancer care trajectory at the treatment phase. The need for emotional and spiritual support may remain constant throughout the course of the illness, and

\section{Table One: Percentage of patients treated with cisplatin-vinorelbine experiencing chemotherapy-related adverse effects}

\begin{tabular}{|c|c|c|c|}
\hline Study (Reference) & \multicolumn{3}{|c|}{ Adverse Events Profile (\%) } \\
\hline & \multicolumn{2}{|c|}{ Winton 2005 (21) } & Douillard \\
\hline & Any Grade & Grade $3 / 4$ & Grade $3 / 4$ \\
\hline
\end{tabular}

Gastrointestinal

\begin{tabular}{|l|l|l|l|}
\hline Diarrhea & 23 & $<1$ & - \\
\hline Nausea & 80 & 10 & 27 \\
\hline Vomiting & 48 & 7 & \\
\hline Constipation & 47 & 3 & - \\
\hline Neurotoxion
\end{tabular}

Neurotoxic

\begin{tabular}{|l|l|l|l|}
\hline Hearing Loss & 21 & 2 & - \\
\hline Sensory neuropathy & 48 & 2 & - \\
\hline Motor neuropathy & 15 & 3 & -
\end{tabular}

Respiratory

\begin{tabular}{|l|l|l|l}
\hline Dyspnea & 18 & 4 & -
\end{tabular}

Hematologic

\begin{tabular}{|l|l|l|l|}
\hline Thrombocytopenia & 32 & 1 & - \\
\hline Anemia & 93 & 7 & 14 \\
\hline Neutropenia & 88 & 73 & 85 \\
\hline Infection & 22 & 1 & 11 \\
\hline Febrile Neutropenia & 7 & 7 & 13 \\
\hline Biochemical &
\end{tabular}

Biochemical

\begin{tabular}{|l|l|l|l|}
\hline ALT elevation & 18 & $<1$ & - \\
\hline Bilirubin elevation & 4 & $<1$ & - \\
\hline Creatinine Elevation & 16 & $<1$ & - \\
\hline
\end{tabular}

General

\begin{tabular}{|l|l|l|l|}
\hline Fatigue & 81 & 15 & - \\
\hline Anorexia & 55 & 10 & 15 \\
\hline Asthenia & - & - & 28 \\
\hline Alopecia & 32 & 0 & 5 \\
\hline Local Toxicity & 35 & 3 & - \\
\hline Phlebitis & - & - & 3 \\
\hline
\end{tabular}

KEY: ALT (Alanine aminotransferase)

Regimens: Winton (2005) used cisplatin $50 \mathrm{mg} / \mathrm{m} 2$ days $1 \& 8$ q4wks + vinorelbine $25 \mathrm{mg} / \mathrm{m} 2 \mathrm{q} 1 \mathrm{wk}$, and Douillard (2006) administered cisplatin $100 \mathrm{mg} / \mathrm{m} 2$ day $1 \mathrm{q} 4 \mathrm{wks} \times 4$ + vinorelbine $30 \mathrm{mg} / \mathrm{m} 2 / \mathrm{q} 1 \mathrm{wk} \times 16$ administrations. 
pain and symptom issues may predominate as the disease or treatments progress. Nurses are in an ideal position to support and advise patients and their families on issues related to treatment decisions. They provide important support and sources of information/guidance for patients who have questions and concerns related to therapy, including the range of available treatment options, the goals of therapy, their prognosis, associated toxicities, and the impact of treatment on quality of life. Nurses should act to ensure, through appropriate teaching and coaching, that patients have a necessary understanding of their treatment options, including the option of no treatment, thereby enabling them to make informed treatment decisions that are congruent with their own values and goals for life and living. Nurses should also provide patients and their families with relevant information materials that are presented in a useable written format. This patient information, developed by various organizations, is available on their websites, including CCO (http://www.cancercare.on.ca/), the American Society of Clinical Oncology (http://www.peoplelivingwithcancer.org), and the National Cancer Institute Cancer Information service (http://cancer.gov/cancerinfo/).

Rates of psychological distress are highest among patients with lung cancer when compared to other types of cancer (Zabora, Brintzenhofeszoc, Curbow, \& Piantadosi, 2001). Depression and anxiety can begin at diagnosis, during the peri-operative period or in the first year post-surgery (Newell, Sanson-Fisher, \& Savolainen, 2002; Yosuke et al., 2003). Because there may be guilt from smoking, morbidity from surgery or a potentially poor prognosis, it is essential that nurses assess patients for their psychosocial, spiritual, and practical needs and develop appropriate management strategies based on institutional and national evidence-based guidelines. As well, nurses should facilitate access to specialized professionals (e.g., social workers, spiritual care providers, supportive services and networks, peer support). Ongoing evaluation of the effectiveness of implemented management strategies is vital to ensure psychosocial, spiritual, and practical needs are met. Having these needs addressed enables patients to better manage their own needs and allows them to cope with the demands imposed by their illness and treatments (Newell et al., 2002). Continuity of nursing care is recommended during adjuvant treatment, as patients are often seen by many different health professionals, which can be a source of stress and patient dissatisfaction (National Cancer Alliance, 1996).

Post-surgical rehabilitation can be introduced before the initiation of adjuvant treatment. Breathlessness post surgery can be effectively assessed and managed by nurses with non-pharmacologic interventions and should be implemented (Bredin et al., 1999). Smoking cessation should also be discussed with patients and their families throughout the cancer journey. This is a source of added anxiety, stress and guilt for patients. As most surgeons emphasize smoking cessation preoperatively, the role of the nurse should be to reinforce smoking cessation after surgery and ensure the patient has access to appropriate information, referrals, and psychosocial support. Nurses can look to The Registered Nurses Association of Ontario (RNAO) best practice guideline on "Integrating smoking cessation into daily nursing practice" (RNAO, 2007) to develop this competency.

\section{Treatment-related toxicities common to patients receiving adjuvant chemotherapy}

Chemotherapy toxicities impact upon patients' quality of life, morbidities, and ability to complete planned treatment. The completion of chemotherapy has been a major issue in clinical trials of adjuvant therapy, with major trials reporting only $50 \%$ to $70 \%$ of patients receiving the planned chemotherapy dose (Douillard et al., 2006; Winton et al., 2005). A multivariate analysis found statistically significant differences in completion on the basis of extent of surgery, gender and age. Women, the elderly, and patients with pneumonectomy were less likely to complete therapy (Alam et al., 2005). Of particular concern are the grade three or four toxicities reported in more than $5 \%$ of patients receiving adjuvant cisplatinvinorelbine (Table One). These include febrile neutropenia, thrombocytopenia, and anemia (Douillard et al., 2006; Winton et al., 2005). Malaise or fatigue is the most common (81\%) and the most severe $(15 \%)$ non-hematologic toxicity associated with cisplatinvinorelbine (Winton et al., 2005). The oncology nurse should keep these factors in mind when supporting patients through treatment.

\section{Nursing assessment of treatment-related toxicities}

During the course of treatment, the oncology nurse plays a critical role in the prevention and early detection of treatment toxicities that impact upon patient quality of life, functional and emotional status, self-care ability, co-morbidities, and ability to complete planned treatment. A focused history and physical assessment prior to the initiation of chemotherapy, and then during the course of treatment, is necessary to determine treatment toxicities and their impact upon patients over time. In addition to treatment-related toxicities, the oncology nurse must also be aware of other common symptoms, which patients may have from the disease itself or as a result of having had a thoracotomy, such as incisional or neuropathic pain. It is also known that $15 \%$ to $44 \%$ of all patients diagnosed with lung cancer have some form of depression (Cooley, 2000; Ginsburg, Quirt, Ginsburg, \& MacKillop, 1995; Yosuke et al., 2003). In addition, sleep-wake disturbances are also common in newly diagnosed lung cancer patients (Cooley, 2000).

Because of the large number of assessment tools available, each Lung Disease Site Team should identify those tools they feel are most useful in their practice and use them consistently to ensure familiarity and usefulness. CCO has mandated that the Edmonton Symptom Assessment Scale (ESAS) be used on all cancer patients. This scale provides an overview of common symptoms in patients with cancer and is easy to complete. Since fatigue is common and may lead to noncompliance with completion of multiple assessment tools, the ESAS provides an opportunity to explore or measure further only those most problematic symptoms and still elicit objective information through a comprehensive assessment. Table Two outlines some other short-item scales and easy-to-complete measurement tools that provide objective information about the emergence and severity of side effects, and the effectiveness of symptom and distress management.

\section{Nursing intervention for treatment-related toxicities}

Optimal nursing management of treatment toxicities should be initiated before the provision of chemotherapy. Patient education related to the prevention and alleviation of treatment toxicity associated with adjuvant cisplatin-vinorelbine may enable patient participation in self-monitoring for the purpose of early detection and prompt reporting of symptoms and concerns. Nurses should be aware of factors that modify treatment compliance (e.g., co-morbidities, extent of surgery, gender and age) and should assist patients in completing treatment through the early detection and meticulous management of treatment toxicities.

Nursing interventions related to the assessment, prevention, and alleviation of chemotherapy toxicities associated with cisplatinvinorelbine have been thoroughly addressed, and management strategies can be found in the Telephone Nursing Practice and Symptom Management Guidelines posted on the CCO website (http://www.cancercare.on.ca/documents/NursingTelephonePractice Guidelines.pdf), the National Comprehensive Cancer Network website (http://www.nccn.org/default.asp), and the Oncology Nursing Society (ONS) website (http:www.ons.org/outcomes/measures/ summaries.shtml).

\section{Follow-up care}

Nurses play a key role in the follow-up and rehabilitation of patients following adjuvant treatment for lung cancer. Rehabilitation may occur within medical or surgical oncology practice or in a 
primary care setting. In addition to providing medical surveillance, nurses are well equipped to provide follow-up on many of the toxicity-related consequences affecting patients who have received adjuvant chemotherapy. A randomized trial of follow-up in lung cancer patients found improved patient satisfaction, earlier detection of symptom progression, better scores for emotional functioning, less severe dyspnea, less peripheral neuropathy, and fewer physician consults in patients also followed by a nurse, compared with patients

\section{Table Two. Assessment tools for the evaluation of chemotherapy-related toxicities and symptom distress}

\begin{tabular}{|l|l|}
\hline Tool & Description \\
\hline \multicolumn{2}{|l|}{ Chemotherapy-Related Toxicities } \\
\hline $\begin{array}{l}\text { Common Terminology Criteria } \\
\text { for Adverse Events (CTCAE) }\end{array}$ & $\begin{array}{l}\text { http://ctep.cancer.gov/reporting/ctc_v30.html - Descriptive terminology developed by the National } \\
\text { Cancer Institute (NCI) that allows for severity grading (scale) for possible treatment related toxicities. }\end{array}$
\end{tabular}

Version 3 or 4.

Performance Status

Karnofsky Performance Status

(KPS) Scale (Karnofsky, Abelmann, Craver, \& Burchenal, 1948)

Eastern Cooperative Oncology

Group (ECOG) Scale

(Oken et al., 1982)

Symptoms

Edmonton Symptom

Assessment Scale (ESAS)

Lung Cancer Symptom Scale

(LCSS)

Symptom Distress

The Memorial Symptom

Assessment Scale (MSAS)

Pain Intensity

The Brief Pain Inventory (BPI)

812400508B603A14\&pn=0EE78204-6646-11D5-812400508B603A14\&method=displayfull

- Patient rates pain intensity with a numeric $0-10$ scale $(0=$ no pain, $10=$ worst possible pain $)$ and

the impact pain exerts on daily activity, mood, walking, sleeping, movement, enjoyment of life and relationships with others.

Depression

Hospital Anxiety And

Depression Scale (HADS)

Dyspnea

Modified Borg Scale

http://ajrccm.atsjournals.org/cgi/content/full/158/5/1557 — This 0 to 10 rated scale has the potential to provide quick, easy, and rapid information about a patient's subjective state of dyspnea.

Sleep-Wake Disturbance

Pittsburgh Sleep Quality

Index (PSQI)

Supportive Care Needs

Supportive Care Needs Survey -

Short Form 34 items (SCNS-SF34)

http://www.newcastle.edu.au/centre/cherp/professionalresources/surveys.html - Provides an assessment of cancer patients' perceived global needs and across the domains of sexuality, psychological, health system and information, physical and daily living, and patient care and support. 
who received only conventional medical follow-up (Moore et al., 2002). Nurses must address a number of issues in conducting followup, including providing information on the importance of follow-up care and its specific goals; pain management; smoking cessation; general cancer-treatment-related disorders including fatigue, physical disability due to surgery or deconditioning, sexual dysfunction, neurologic and musculoskeletal disorders, hearing loss, and cognitive impairment; healthy lifestyle education; issues related to decreased lung capacity; supportive counselling; and signs and symptoms that may indicate cancer recurrence.

Nurses should provide information and support to patients as they deal with returning to work, and other survivorship issues. Lung Cancer Online provides information on common survivorship issues and how to support patients at this point in the continuum of care (http://www.lungcanceronline.org/surviving/index.html). Nurse-led follow-up clinics for patients who have completed adjuvant

\section{References}

Alam, N., Darling, G., Shepherd, F.A., Mackay, J.A., Evans, W.K., \& Lung Cancer Disease Site Group of Cancer Care Ontario's Program in Evidence-Based Care. (2006). Postoperative chemotherapy in nonsmall cell lung cancer: A systematic review. The Annals of Thoracic Surgery, 81(5), 1926-1936.

Alam, N., Shepherd, F.A., Winton, T., Graham, B., Johnson, D., Livingston, R., et al. (2005). Compliance with post-operative adjuvant chemotherapy in non-small cell lung cancer. An analysis of National Cancer Institute of Canada and intergroup trial JBR.10 and a review of the literature. Lung Cancer, 47(3), 385-394.

Bredin, M., Corner, J., Krishnasamy, M., Plant, H., Bailey, C., \& A'Hern, R. (1999). Multicentre randomized controlled trial of nursing intervention for breathlessness in patients with lung cancer. British Medical Journal, 318, 901-904.

Canadian Association of Nurses in Oncology. (2002). CANO/ACIO Practice Standards. Vancouver, BC: Author.

Carlson, L.E., \& Bultz, B.D. (2004). Efficacy and medical cost offset of psychosocial interventions in cancer care: Making the case for economic analyses. Psychooncology, 13, 837-849.

Cooley, M.E. (2000) Symptoms in adults with lung cancer. A systematic research review. Journal of Pain and Symptom Management, 19(2), 137-153.

Douillard, J.Y., Rosell, R., De Lena, M., Carpagnano, F., Ramlau, R., Gonzales-Larriba, J.L., et al. (2006). Adjuvant vinorelbine plus cisplatin versus observation in patients with completely resected stage IB-IIIA non-small-cell lung cancer (Adjuvant Navelbine International Trialist Association [ANITA]): A randomised controlled trial. The Lancet Oncology, 7(9), 719-727.

Douillard, J.Y., Rosell, R., De Lena, M., et al. (2005). ANITA: Phase III adjuvant vinorelbine $(\mathrm{N})$ and cisplantin $(\mathrm{P})$ versus observation (OBS) in completely resected (stage I-III) non-small cell lung cancer (NSCLC) patients (pts): Final results after 70 months median follow-up. Proceedings of the American Society for Clinical Oncology, 23, 624S. A7013.

Fitch, M. (2003). Supportive care: Rebalancing efforts. In T. Sullivan, W. Evans, H. Angus, \& A. Hudson (Eds.), Strengthening the quality of cancer services in Ontario (pp. 141-163). Ottawa, ON: CHA Press.

Fitch, M. (1994). Providing supportive care for individuals living with cancer. Toronto, ON: Ontario Cancer Treatment and Research Foundation.

Ginsburg, M.L., Quirt, C., Ginsburg, A.D., \& MacKillop, W.J. (1995). Psychiatric illness and psychosocial concerns of patients with newly diagnosed lung cancer. Canadian Medical Association Journal, 152(5), 701-708. chemotherapy should be considered. Further research is required to determine the frequency and nature of the health monitoring required to properly support patients with consistent follow-up care.

\section{Conclusion}

Members of the Lung DSG noted that in their clinical practice, it was difficult for patients to complete adjuvant cisplatin/vinorelbine chemotherapy due to the side effects and felt that nursing-specific guidance related to these concerns would aid in improving care for these patients. This report highlights the evidence on the toxicity and adverse events that are caused by adjuvant chemotherapy and discusses major side effects and symptoms that are amenable to nursing assessment and intervention. Oncology nurses are vital, whether in the primary or navigator roles, to communicate the importance of treatment completion to patients, to help remedy toxicity, and to support patients and families across the continuum of care.
Karnofsky, D., Abelmann, W., Craver, L., \& Burchenal, J. (1948). The use of nitrogen mustard in the palliative treatment of cancer. Cancer, 1, 634-656.

Kurtz, M.E., Kurtz, J.C., Given, C.W., \& Given, B. (2006). Predictors of use of health care services among elderly lung cancer patients: The first year after diagnosis. Support Care Cancer, 14, 243-250.

The London and South East Lung Cancer Forum for Nurses. (2004). Guidelines on the role of the specialist nurse in supporting patients with lung cancer. European Journal of Cancer Care, 13, 344-348.

Moore, S., Corner, J., Haviland, J., Wells, M., Salmon, E., Normand, C., et al. (2002). Nurse-led follow-up and conventional medical follow-up in management of patients with lung cancer: Randomized trial. British Medical Journal, 325, 1145.

National Cancer Alliance. (1996). Patient-centred services? What patients say. Oxford: NCA.

Newell, S.A., Sanson-Fisher, R.W., \& Savolainen N.J. (2002). Systematic review of psychological therapies for cancer patients: Overview and recommendations for future research. Journal of the National Cancer Institute, 94(8), 558-584.

Oken, M.M., Creech, R.H., Tormey, D.C., Horton, J., Davis, T.E., McFadden, E.T., et al. (1982). Toxicity and response criteria of the Eastern Cooperative Oncology Group. American Journal of Clinical Oncology, 5, 649-655.

Quinn, S. (1999). Lung cancer: The role of the nurse in treatment and prevention. Nursing Standard, 13(41), 49-54.

Registered Nurses Association of Ontario. (2007). Integrating smoking cessation counselling into daily nursing practice. Revised. Toronto, ON: Author.

Shepherd, F., Winton, T., Livingston, R., et al. (2004). The impact of adjuvant vinorelbine (VIN) and cisplatin (CIS) on quality of life (QoL): Results from the National Cancer Institute of Canada Clinical Trials Group Trial BR.10 randomized trial of VIN/CIS versus observation in stage IB and II non-small cell. Annals of Oncology, 15(Suppl. 3), A6270.

Winton, T., Livingston, R., Johnson, D., Rigas, J., Johnston, M., Butts, C., et al. (2005). Vinorelbine plus cisplatin vs. observation in resected non-small-cell lung cancer. New England Journal of Medicine, 352(25), 2589-2597.

Yosuke, U., Ichiro, M., Kanji, N., Yutaka, N., Tatsuo, A., \& Hitoshi, O. (2003). Depression and psychological distress in patients during the year after curative resection of non-small-cell lung cancer. Journal of Clinical Oncology, 21(1), 69-77.

Zabora, J., Brintzenhofeszoc, K., Curbow, B., \& Piantadosi, S. (2001). The prevalence of psychological distress by cancer site. Psychooncology, 10, 19-28. 